\title{
A Parametric Study on the Elliptical hole Effects of Laminate Composite Plates under Thermal Buckling Load
}

https://doi.org/10.1515/secm-2020-0019

Received Feb 26, 2020; accepted May 03, 2020
Abstract: In this study, a thermal buckling analysis of laminate composite square plate was performed with elliptical hole cutout using the finite element method. Graphite/Epoxy laminate plate used in this study is symmetrical stacking sequence plate $\left[(0 / 90)_{2}\right]_{s}$. This laminate square plate was subjected to temperature loading with clamped support on all edges. Moreover, the parameters considered were fiber orientation $(\theta), \mathrm{a} / \mathrm{b}$ ratio (elliptical hole), elliptical hole inclination $(\varphi)$, thermal expansion coefficient ratio $\left(\alpha_{1} / \alpha_{2}\right)$, and thickness of plates $(t)$. The results showed that as the thermal expansion coefficient ratio changes, the elliptical hole ratio and the elliptical hole inclination have inconsequential effects on the performance of the resistance of laminate composite plates. The maximum values of thermal buckling amplification factor were obtained when the ratio $a / b=1.0$, which is a circle cutout, while the minimum values were obtained when the ratio $\mathrm{a} / \mathrm{b}=0.5$, regardless of the thickness of plates. Moreover, the plate with elliptical or circle cutout hole provides about $4 \%$ to $9 \%$ higher buckling resistance than that of the plate without hole cutout, because when subjected to temperature loading the plate with hole can release stress better than the plate without hole.

Keywords: Thermal buckling, Laminate composite, Elliptical hole, FEM

\footnotetext{
${ }^{\star}$ Corresponding Author: WooYoung Jung: Gangneung-Wonju National University, College of Engineering, Building No. 2, Room 110, Gangneung city, Gangwon province [25457], Korea; Email: woojung@gwnu.ac.kr

Buntheng Chhorn: Gangneung-Wonju National University, College of Engineering, Building No. 2, Room 128, Gangneung city, Gangwon province [25457], Korea; Email: buntheng.chhorn@yahoo.com
}

\section{Introduction}

The use of composite laminate is notably increasing in commercial aircraft, automobile, marine industry, robotic arms, and civil engineering [1], due to its high strength-toweight ratio, high stiffness, low coefficient of thermal expansion, and high fatigue resistance [2, 3]. A clear understanding of its structural behavior is essential, such as the deflection, the through-thickness distributions of stress and strain buckling, loads and modal characteristics, the large deflection behavior, and of enormous necessity for attaining strong, reliable multi-layered structures, the failure characteristics. But depending on their anisotropic and heterogeneous nature, laminate composite plates are more intricate in analysis than homogeneous plates. In fact, owing to practical requirements, hole cutouts are often needed in structural components to reduce weigh and increase efficiency in structures. For example, hole cutouts in wing spars and cover panels of commercial transport wings and military fighter wings are required to offer access for electrical lines, hydraulic lines, and damage inspection [4]. Although the laminate composite is often subjected to elevated temperature environments, which easily induce buckling, the study on thermal buckling of laminate composite plates with elliptical/circle hole cutout is still not adequate. Buckling is one of the main failure modes of laminate composite plates when they are under membrane stress caused by temperature loads, mechanical loads, and thermo-mechanical loads. Therefore, the buckling resistance of laminate composite is the governing factor in design [5-15]. Also proposed some new techniques in predicting the critical buckling of plates with various thickness, aspect ratio and arbitrary loading.

When plates are subjected to elevated temperature environments, the thermal stresses of laminate composite plates are developed at the edges of the plates, owing to the constraint of thermal expansion coefficients. These thermal stresses cause thermal buckling loads that affect the structural behavior of the plates, which result in buckling of the plates. Thus, Topal and Uzman [16] studied the

əopen Access. (c) 2020 B. Chhorn and W. Jung, published by De Gruyter. (cc) BY 
optimal design of laminate composite plates with circular hole cutouts subjected to thermal buckling load. Moreover, the first order shear deformation was used for the finite element analysis. It demonstrated that as the aspect ratio increases, the optimum fiber orientation and critical buckling load gradually decrease. Avic et al. $[17,18]$ were interested in studying the rectangular symmetric and asymmetric laminate composite plates that contain a circular hole with clamped and simply supported edges. The first order shear deformation with eight-node Lagrangian FE technique was used to analyze the thermal buckling. Chen et al. [19] studied the thermal buckling of antisymmetric cross-ply laminate composite plates with circular hole. They showed that the effects of thermal expansion and thickness ratio have no influence on the relative buckling temperature. Also, their paper illustrated that the thermal buckling load increased with the increase of elastic modulus ratio in plates without a hole. Shaterzadeh et al. [20] investigated the thermal buckling of symmetric and antisymmetric laminate composite plates with a circular cutout. Code developed in MATLAB software was used to analyze thermal buckling with the first order shear deformation theory. It proved that the critical thermal buckling loads of symmetric plates are smaller than those of antisymmetric plates. It was also found that for small holes $(d / a \leq 0.1)$, the influence of hole is inconsequential for the cases of decreased critical thermal buckling load, but as the hole size increases, its effect becomes more substantial.

Although many previous researches have focused on the thermal buckling of laminate composite plates with circular holes, only a few studies have focused on the plates with elliptical hole cutout. Kumar et al. [21] carried out buckling analysis of woven-glass-polyester laminate composite plates with elliptical/circular hole. They showed that the buckling loads decreased when the ratio of minor axis to length of plate (c/a) and ratio of major axis to length of plate $(\mathrm{b} / \mathrm{a})$ increased. In addition, the angleply laminate composite plates have smaller resistance to buckling than the cross-ply composite plate. Ouinas and Achour [22] were interested in studying the buckling load on square composite plates with an elliptical/circular hole. They maintained that the designers must avoid the orientation angle of the elliptical notch smaller than $45^{\circ}$, if they wanted to obtain high resistance to buckling load. Kumar et al. [5] studied the thermal buckling of rectangular laminate composite plate with elliptical/circular cutout. Seven different quasi-isotropic laminates were used to analyze the thermal buckling load. The parameters used in their study are the orientation of the elliptical cutout, plate aspect ratio, and plate length/thickness ratio. However, the results presented in previous study illustrated that the effect of plate length/thickness, plate aspect ratio, cutout size, orientation of cutout, and elliptical hole aspect ratio required more detailed investigation.

In the present study, the thermal buckling of square laminate composite plate with elliptical/circular hole cutout was considered. The Graphite/Epoxy laminate plate used in this study was symmetrical stacking sequence plate $\left[(0 / 90)_{2}\right]_{s}$. This laminate square plate was subjected to temperature loading with clamped support along all four edges. The parameters studied were the effect of fiber orientation $(\theta)$, ratio a/b (elliptical hole), elliptical hole inclination $(\varphi)$, thermal expansion coefficient ratio $\left(\alpha_{1} / \alpha_{2}\right)$, and thickness of plate $(\mathrm{t})$.

\section{Finite Element Modeling}

This study considered a thin laminate composite square plate of length $100 \mathrm{~mm}$, width $100 \mathrm{~mm}$, and thickness t $=1 \mathrm{~mm}$ (see Figure 1), and having an elliptical hole at its center. The Graphite/Epoxy material [23] had the properties $\mathrm{E}_{11}=181 \mathrm{GPa}, \mathrm{E}_{22}=10.3 \mathrm{GPa}, \mathrm{G}_{12}=\mathrm{G}_{13}=7.17 \mathrm{GPa}, \mathrm{G}_{23}$ $=6.2 \mathrm{GPa}, v_{12}=0.28$, and was laid up in 8 plies.

The present plate was subjected to temperature loading on the surface of the plate. Also, the finite element commercial software ABAQUS 6.13 was used for the analysis. The plates were modeled using an eight node shell element (S8R5). The 2381 SHELL elements had 8 nodes with 6 degrees of freedom at each node; rotation around the nodal $x$, $\mathrm{y}, \mathrm{z}$ axes, and translations along the $\mathrm{x}, \mathrm{y}, \mathrm{z}$ directions. The modeling was undertaken in plane stress. Also, the plate contained 8 plies of lamina; each ply having a thickness of $0.125 \mathrm{~mm}$. Figure 2 shows the orientation of the symmetric cross-ply laminate composite plate.

In the practical requirements of composite plates in the real world, different shapes and sizes of holes can be used for design purpose. The elliptical hole used in this study was located at the center of the plate. Thus, the differences of the elliptical hole orientations and proportions on the thermal buckling were considered. The elliptical hole orientations were represented by the angle of inclination of the major axis of the elliptical hole to the $\mathrm{x}$-axis, and the variation was from $0^{\circ}$ to $90^{\circ}$. When the inclination angle $\varphi=0^{\circ}$, the major axis of the elliptical hole was parallel to the x-axis; when the inclination angle $\varphi=90^{\circ}$, the major axis was perpendicular to the $\mathrm{x}$-axis. The proportions of the elliptical hole were represented by the dimensions of the minor and major diameters of the elliptical hole, which were denoted by 'a' and ' $b$ ', respectively. The parameter ' $b$ ' 

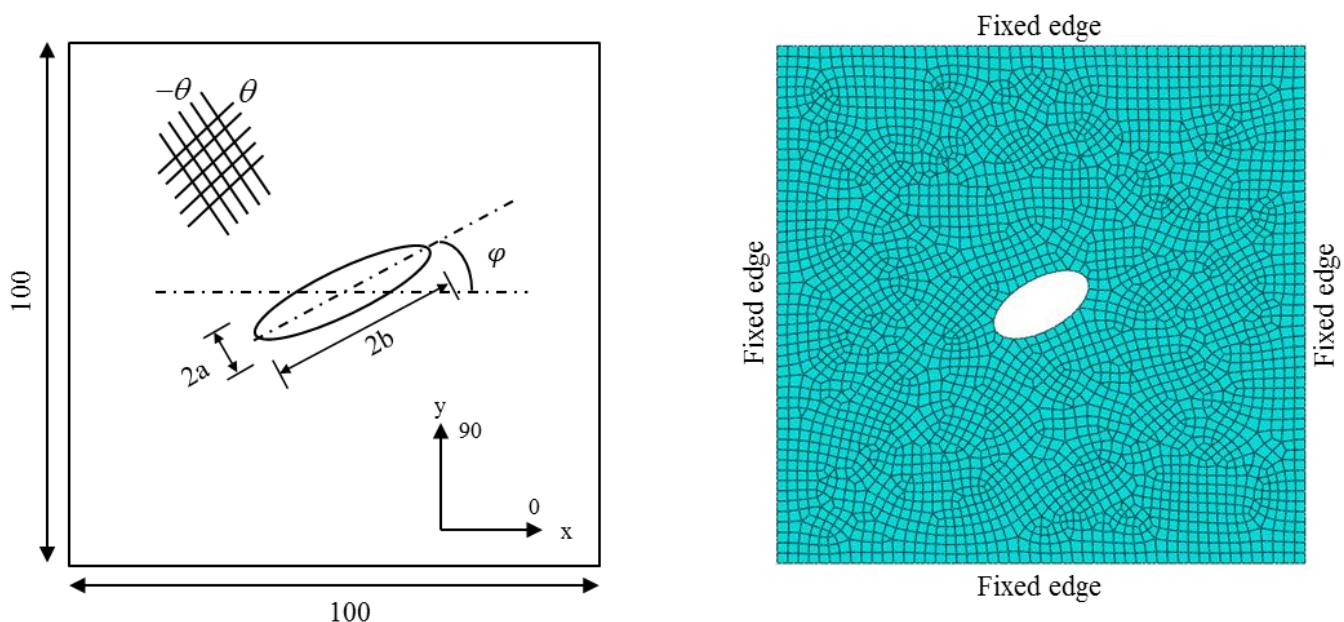

Figure 1: Geometric modeling and meshing of the plate with elliptical hole.

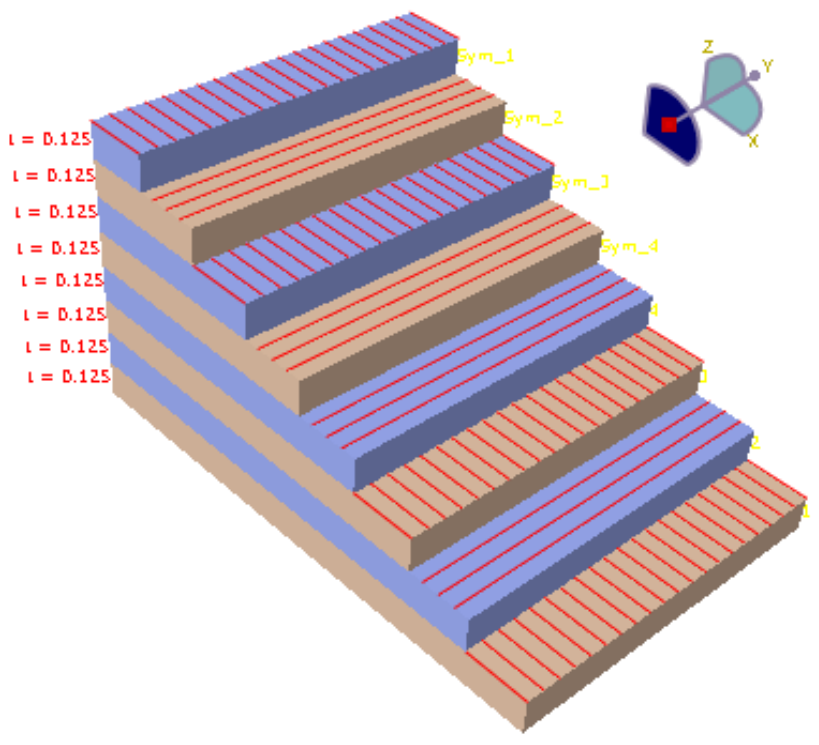

Figure 2: Fiber orientation of the laminate plate.

remained constant, i.e. $10 \mathrm{~mm}$, while the parameter 'a' was varied from $1 \mathrm{~mm}$ to $10 \mathrm{~mm}$.

\section{Numerical Parametric Study of Laminate Composite Plates}

\subsection{Influence of the geometric hole aspect ratio $(a / b)$ on the thermal buckling load}

Figure 3 shows the effect of the geometric ratio $(a / b)$ of an ellipse on the variation of thermal buckling load for several hole orientations. The major axis of the ellipse was of

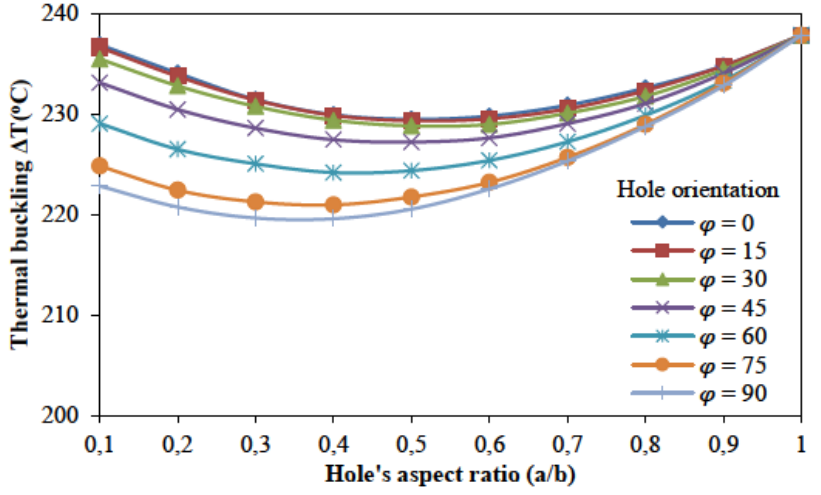

Figure 3: Effect of hole aspect ratio $(a / b)$ on the thermal buckling load.

constant length $(b=10 \mathrm{~mm})$, while the length of the minor axis of the ellipse (a) was varied. The laminate composite material used in this case was symmetrical with types $\left[(0 / 90)_{2}\right]_{s}$. This figure is divided into two cases, case 1 elliptical hole orientation $\varphi \leq 45^{\circ}$, and case 2 elliptical hole orientation $\varphi>45^{\circ}$. The figure illustrates that for $\varphi>45^{\circ}$, when the aspect ratio of elliptical hole was between $(0.1$ and 0.4), the thermal buckling load decreased slowly. For $\varphi \leq 45^{\circ}$, the decrement occurred up to the hole's aspect ratio of 0.5. Beyond this aspect ratio, the curve increased exponentially. The maximum thermal buckling loads were obtained for the largest ratio $(\mathrm{a} / \mathrm{b}=1)$, which was the circular hole, and which was identical in all cases of hole orientation. Meanwhile, the minimum thermal buckling load in the case of hole orientation $\varphi>45^{\circ}$ was obtained when the ratio $\mathrm{a} / \mathrm{b}$ was equal to 0.4 , and in the cases of hole orientation $\varphi \leq 45^{\circ}$, was equal to 0.5 . Moreover, it was observed that the laminate composite plates with hole orientation $\varphi$ $=0^{\circ}$ showed the highest resistance to buckling; when $\varphi=$ 

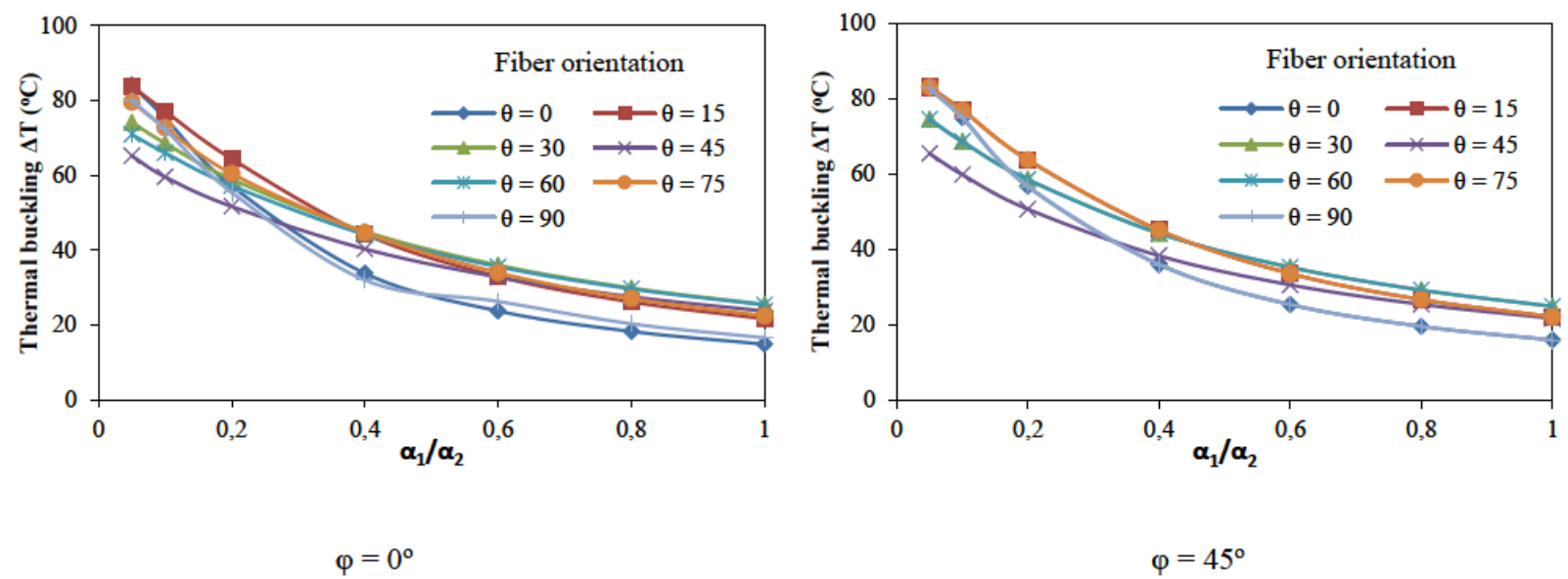

Figure 4: Effect of thermal expansion coefficient on the thermal buckling load.

$90^{\circ}$, it provided the lowest values of thermal buckling load. Therefore, it can be concluded that the composite laminate plate with smaller elliptical hole orientation yields higher buckling resistance.

\subsection{Influence of the thermal expansion coefficient}

To highlight the effect of the thermal expansion coefficient on the thermal buckling load of the laminate composite plates with ratio $\mathrm{a} / \mathrm{b}=0.4$, two cases of elliptical hole inclination, $\varphi=0^{\circ}$ and $45^{\circ}$, were considered. Figure 4 shows the variation of the fiber orientation in these cases. The figure shows that the thermal buckling load decreased quasilinearly with the increase of the thermal expansion coefficient ratio, while it was similar for all cases of fiber orientation for both inclinations of elliptical hole angle $\varphi=0^{\circ}$ and $45^{\circ}$. Exceptional cases occurred when the fibers were orientated $\theta=0^{\circ}$ and $90^{\circ}$, where it was observed that the thermal buckling load decreased rapidly with the increase of thermal expansion coefficient ratio (0.05 up to 0.4). Beyond this value and up to $\alpha_{1} / \alpha_{2}=1.0$, these curves showed the same trend as the other curves. Thus, it can be concluded that the thermal buckling of plates with plies orientation $\theta=0^{\circ}$ and $90^{\circ}$ are sensitive to the change of ratio of thermal expansion coefficient. This is due to the in-plane thermal forces of plates with stacking sequence $\theta=0^{\circ}$ and $90^{\circ}$ increasing more rapidly than those of plates with other stacking sequence, when the thermal expansion coefficient ratio increases. Consequently, they are vulnerable to buckling. In addition, it shows that the maximum values were obtained when the thermal expansion coefficient's ratio $\alpha_{1} / \alpha_{2}=0.05$, while the lowest values were ob- tained when $\alpha_{1} / \alpha_{2}=1.0$. Hence, it can be seen that the higher the thermal expansion coefficient ratio, the lower the resistance of the laminate composite plate subjected to buckling for both cases of elliptical hole inclination. In the case $\varphi=0^{\circ}$, it can also be noted that the plate with the fiber orientation $\theta=0^{\circ}$ and $15^{\circ}$ showed the highest resistance when $\alpha_{1} / \alpha_{2}=0.05$. Then, the curve was remarkable when $\alpha_{1} / \alpha_{2} \geq 0.4$, the plates with fiber angle $\theta=30^{\circ}$ and $60^{\circ}$ showed the highest resistance to bucking, while the lowest values were obtained when the stacking sequence of plate was $\theta=0^{\circ}$ and $90^{\circ}$. In the case of $\varphi=45^{\circ}$, when $\alpha_{1} / \alpha_{2}=$ 0.05 , the highest values were for the plate with fiber angle $\theta=0^{\circ}, 15^{\circ}, 75^{\circ}$, and $90^{\circ}$. When the $\alpha_{1} / \alpha_{2}$ ratio exceeded 0.4 and up to 1.0 , the results obtained were similar to the results of the plate with elliptical hole inclination $\varphi=0^{\circ}$.

Figure 5 demonstrates the influence of the thermal expansion coefficient ratio of laminate composite material on the variation of thermal buckling load for several values of the geometric ratio a/b. The laminate composite material used in this case was symmetric, with stacking sequence $\left[(0 / 90)_{2}\right]_{s}$. The transverse thermal expansion coefficient was maintained constant, and the longitudinal thermal expansion coefficient was varied. Also, two types of elliptical hole inclination, $\varphi=0^{\circ}$ and $45^{\circ}$, were studied. Figure 5 shows that the case $\varphi=0^{\circ}$ shows that the thermal buckling load decreased quasi-linearly with increasing thermal expansion coefficient ratio, and was identical in all cases of hole ratios $\mathrm{a} / \mathrm{b}$. These results were due to the increase in in-plane force, which resulted in the increment of induced membrane forces. The maximum values of thermal buckling load were obtained when the thermal expansion coefficient ratio was 0.05 , while the smallest values were obtained when the longitudinal thermal expansion coefficient was equal to the transverse thermal 

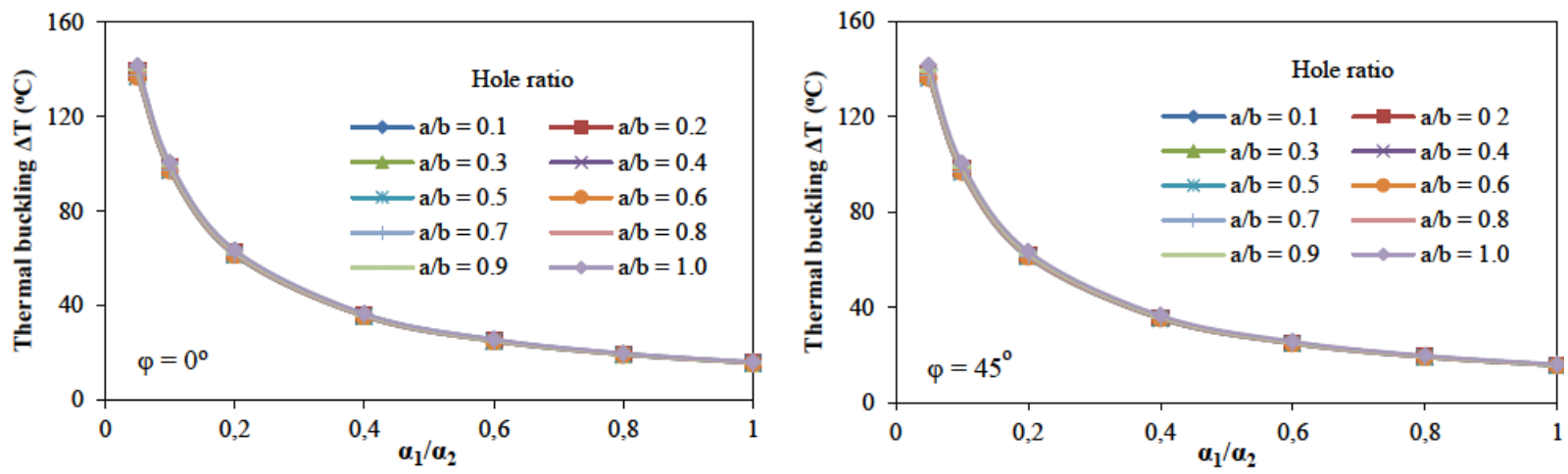

Figure 5: Effect of thermal expansion coefficient with various hole ratios $(a / b)$.

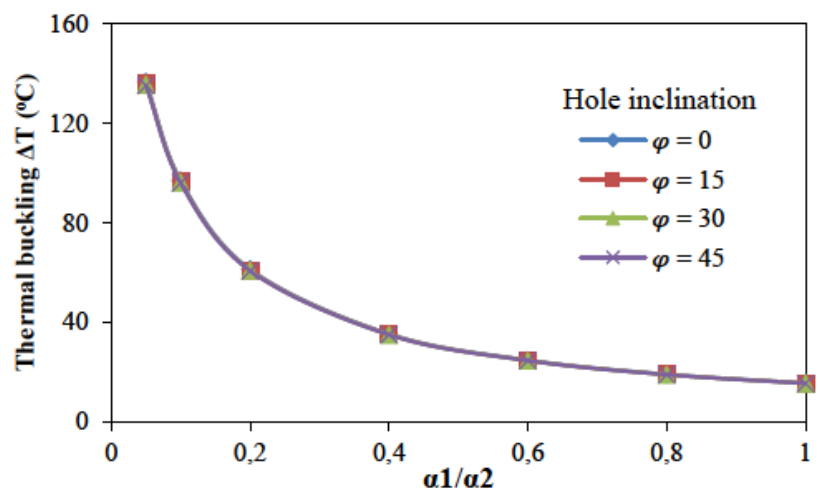

Figure 6: Effect of thermal expansion coefficient with various hole inclinations (in the case $\mathrm{a} / \mathrm{b}=0.4$ ).

expansion coefficient. Furthermore, the effect of the ratio $\mathrm{a} / \mathrm{b}$ was also considered. This case illustrated that for all ratios $\mathrm{a} / \mathrm{b}$, the thermal buckling loads were the same for the entire range of thermal expansion coefficient ratio. Similar curves are shown in cases where the elliptical hole orientation is $\varphi=45^{\circ}$. The results showed that the thermal buckling load of each elliptical hole inclination was identical for all thermal expansion coefficient ratios. Figure 6 shows the relationship between the thermal buckling load and the thermal expansion coefficient ratio with various hole inclinations $(\varphi)$. The ratio of elliptical hole $(\mathrm{a} / \mathrm{b}=0.4)$ was selected to use in this case. It showed that the thermal buckling of plates with elliptical hole inclinations $\varphi=$ $0^{\circ}, 15^{\circ}, 30^{\circ}$, and $45^{\circ}$ were similar for all cases of thermal expansion coefficient. According to Figures 5 and 6, it can be concluded that as the thermal expansion coefficient ratio changes, the elliptical hole ratio $(a / b)$, as well as the elliptical hole inclination $(\varphi)$, have almost no effect on the resistance of laminate composite plates to buckling.

\subsection{Influence of the layer thickness of laminate composite plates}

Figure 7 shows the thermal buckling load with regard to the thickness of laminate composite plates with several fiber orientations. Also, two cases of hole angle, $\varphi=0^{\circ}$ and $45^{\circ}$, with geometric ratio $(\mathrm{a} / \mathrm{b}=0.4)$ were considered. The figure shows that the thermal buckling load increased progressively and linearly with the increase of thickness of the laminate composite plate for both cases of $\varphi=0^{\circ}$ and $45^{\circ}$, regardless of the fiber orientation and hole inclination. This was due to the increase of laminate composite plate stiffness. Moreover, in the case where the elliptical hole angle $\varphi=0^{\circ}$, note that the maximum values of thermal buckling load were obtained when the fiber orientation $\theta$ $=0^{\circ}$. In contrast, the lowest values were obtained when the laminate composite plates were orientated with $\theta=45^{\circ}$, regardless of the thickness of plates. In the case where the elliptical hole inclination $\varphi=45^{\circ}$, the highest resistance of laminate composite plates was obtained when the fiber was set as $\theta=0^{\circ}, 15^{\circ}, 75^{\circ}$, and $90^{\circ}$, while the lowest resistances of laminate composite plates were obtained when the fibers were orientated at $\theta=45^{\circ}$, for all cases of plate thickness. Thus, in this case, to avoid obtaining the lowest buckling resistance of the laminate composite plates, the ply orientation must not be set at $\theta=45^{\circ}$.

To demonstrate the effect of the ratio $(\mathrm{a} / \mathrm{b})$ of laminate composite plates with respect to the thickness, two cases of hole inclination were studied. In the first case, the major axis of the elliptical holes was set parallel to the $\mathrm{x}$ direction. In the second case, the major axis of the elliptical hole was taken as $\varphi=45^{\circ}$, compared to the $\mathrm{x}$-direction. Figures 8 and 9 demonstrate the results obtained with symmetry of stacking sequence type $\left[(0 / 90)_{2}\right]_{s}$. In these two figures, the variation of the amplification factor of the thermal buckling load is represented. Also, the thermal buck- 


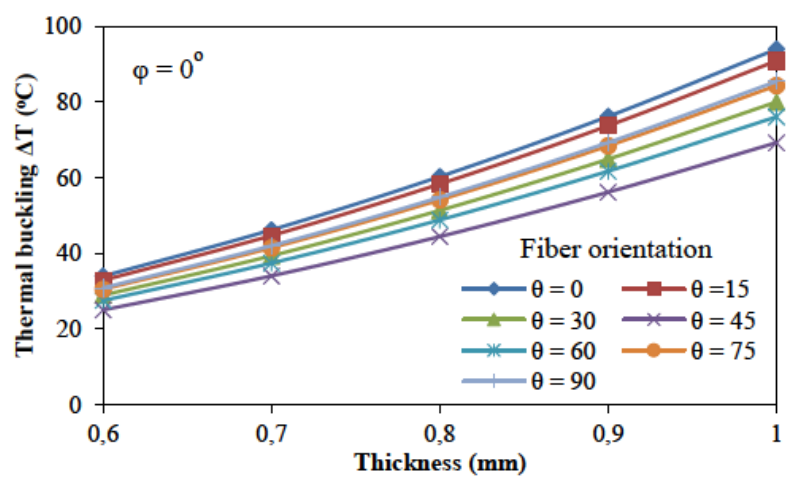

Figure 7: Effect of layer thickness with various fiber orientations.

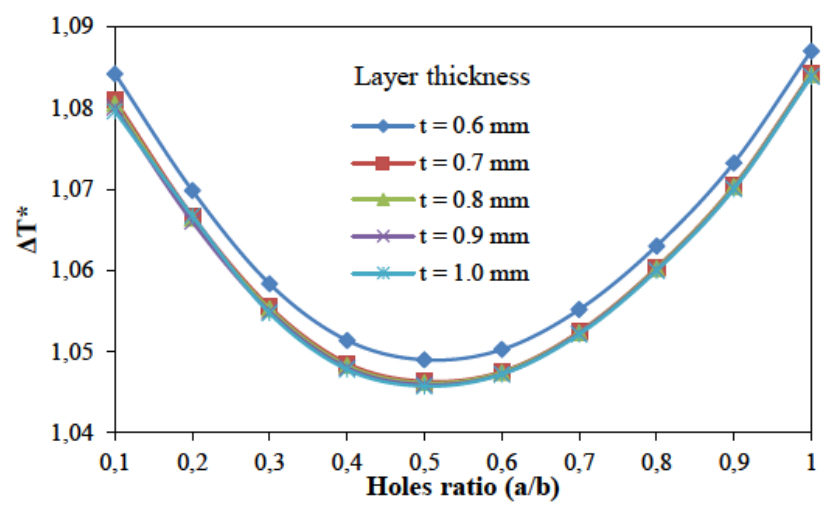

Figure 8: Effect of hole ratio (a/b) on the thermal buckling amplification factor $\left(\varphi=0^{\circ}\right)$.

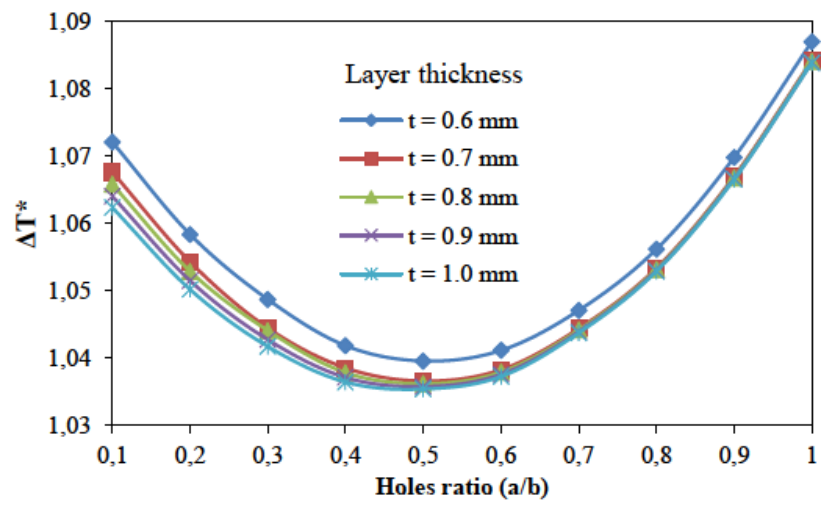

Figure 9: Effect of hole ratio (a/b) on the thermal buckling amplification factor $\left(\varphi=45^{\circ}\right)$.

ling amplification factor is denoted by the following:

$$
\Delta T^{\star}=\frac{\Delta T_{w t h}}{\Delta T_{w h}}
$$

where, $\Delta T_{w h}$ and $\Delta T_{w t h}$ are the thermal buckling load of the plates with and without an elliptical hole, respectively.

Note that the presence of the elliptical hole with two different orientations in the same laminate composite plate provided almost the same results of the thermal

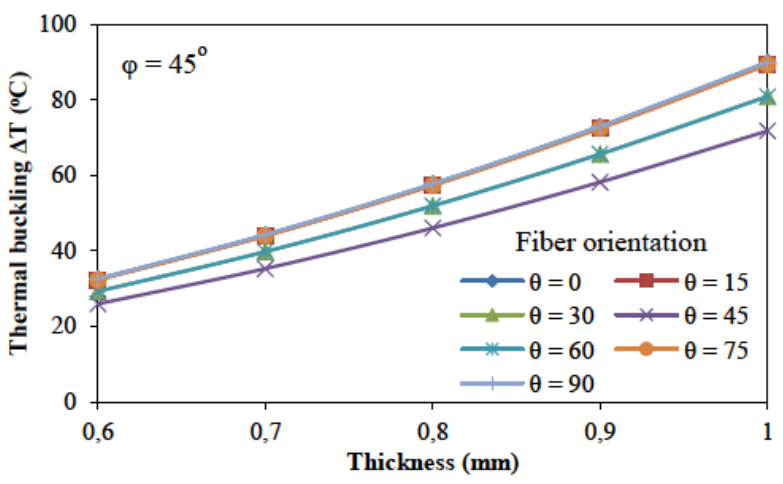

buckling amplification factor. In the case where the elliptical hole inclination was set parallel to the x-direction, the curve of the amplification factor was divided into two stages, as shown in Figure 8. In the first stage, it was observed that the thermal buckling amplification factor decreased proportionally to the increment of the ratio $\mathrm{a} / \mathrm{b}$, from (0.1 to 0.5). Above this value and up to 1 , which was the second stage, the factor $\Delta T^{\star}$ increased rapidly. In addition, the figure illustrates that the curve for the plate with thickness equal to 0.6 provided the highest thermal buckling amplification factor. Beside the laminate composite plate with thickness 0.6 , the $\Delta T^{\star}$ values were similar as the ratio a/b increased from ( 0.1 up to 1.0 ). Therefore, it can be noted that in the case $t \geq 0.7 \mathrm{~mm}$, the thickness of plate has almost no effect on the thermal buckling amplification factor. The maximum $\Delta T^{*}$ values are obtained when the hole ratio $\mathrm{a} / \mathrm{b}$ is equal to 1.0 , i.e. a circular hole.

Figure 9 illustrates the variation of thermal buckling amplification factor with respect to the ratio $a / b$. It is observed that this figure shows the same trend as Figure 8. In this case, the minimum values of amplification factor were obtained when the ratio $\mathrm{a} / \mathrm{b}$ equaled 0.5 (elliptical hole), while the highest $\Delta T^{\star}$ values of $108.5 \%$ were obtained when the ratio $\mathrm{a} / \mathrm{b}=1$ (circular hole). These results were due to the smaller dimension of the elliptical hole, which can release lower stress than the larger circular hole. Furthermore, depending on the dimension of the hole, it can be seen that the plates with elliptical or circular hole offered about $4 \%$ to $9 \%$ higher thermal buckling load than the plates without a hole. These results under temperature loading were due to the plates with hole being able to release stress better than the plates without hole. This means that the hole cutout under temperature loading works as a free boundary condition that allows the plate to expand along the in-plane direction, rather than out-of-plane. 


\section{Conclusions}

The application and design parameters have a great effect on the failure mode of a structure. The present study investigated the thermal buckling of graphite/epoxy composite laminate square plates with elliptical hole. The effect of fiber orientation $(\theta)$, elliptical hole axes ratio $a / b$, elliptical hole inclination $(\varphi)$, thermal expansion coefficient ratio $\left(\alpha_{1} / \alpha_{2}\right)$, and thickness of plate $(\mathrm{t})$ were focused on as the design parameters. From this study, the following conclusion can be made:

- The higher the hole inclination value, the smaller the thermal buckling resistance of the laminate composite plate.

- The effect of the thermal expansion coefficient on the critical thermal buckling load greatly depends on the fiber orientation. Additionally, the resistance of laminate composite plates with stacking sequence $\theta=0^{\circ}$ and $90^{\circ}$ were the most sensitive to the change of thermal expansion coefficient ratio, compared to other stacking sequences.

- The ratio of the elliptical hole $\mathrm{a} / \mathrm{b}$, as well as the elliptical hole inclination, showed almost no effect on the resistance of laminate composite plates as the thermal expansion coefficient ratio changed.

- For all cases of plate thickness, to avoid obtaining the lowest buckling resistance of laminate composite plates, the ply orientation must not be set at $\theta=$ $45^{\circ}$.

- In the case of thickness greater than $0.6 \mathrm{~mm}$, the thickness of laminate composite plates has negligible effect on the thermal buckling amplification factor.

- The maximum values of thermal buckling amplification factor were obtained when the ratio $\mathrm{a} / \mathrm{b}=1$, which is a circle cutout; while the minimum value was obtained when the ratio $\mathrm{a} / \mathrm{b}=0.5$, regardless of the thickness of plates.

- The plate with elliptical or circular hole provides about $4 \%$ to $9 \%$ higher buckling resistance than that of the plate without hole cutout. This is because when subjected to temperature loading, the plates with hole can release stress better than the plate without hole.

Acknowledgement: This present work was supported by the National Research Foundation [NRF] grant funded by the Korea government [MEST] [No.2017R1A2B3008623].

\section{References}

[1] Kweon JH, Jung JW, Kim TH, Choi JH, Kim DH. (2006), "Failure of carbon composite-to-aluminum joints with combined mechanical fastening and adhesive bonding”, Composite Structures., 75(1-4), 192-198. https://doi.org/10.1016/ j.compstruct.2006.04.013.

[2] Aniskevich K, Aniskevich A, Arnautov A and Jansons J. (2012), "Mechanical properties of pultruded glass fiber-reinforced plastic after moistening”, Composite Structures., 94(9), 2914-2919. https://doi.org/10.1016/j.compstruct.2012.04.030.

[3] Fiore, V., Scalici, T., Di Bella, G., \& Valenza, A. (2015), “A review on basalt fiber and its composites", Composites Part B: Engineering., 74, 74-94. https://doi.org/10.1016/j.compositesb.2014.12. 034.

[4] Zhang, Y. X., \& Yang, C. H. (2009), "Recent developments in finite element analysis for laminated composite plates", Composite Structures., 88(1), 147-157. https://doi.org/10.1016/j. compstruct.2008.02.014.

[5] Kumar, R. Vijaya, and G. Krishnamohana Rao. (2018), “Thermal Buckling Analysis of Laminated Composite Plate with Square/Rectangular, Elliptical/Circular Cutout”, Materials Today: Proceedings., 5(2), 5354-5363. https://doi.org/10.1016/ j.matpr.2017.12.121.

[6] Saberi, S., Memarzadeh, P., \& Zirakian, T. (2019), "Study of buckling stability of cracked plates under uniaxial compression using singular FEM", Structural Engineering and Mechanics, 69(4), 417426. DOI: https://doi.org/10.12989/sem.2019.69.4.417.

[7] Fellah, M., Draiche, K., Houar, M. S. A., Tounsi, A., Saeed, T., Alhodaly, M. S., \& Benguediab, M. (2019), "A novel refined shear deformation theory for the buckling analysis of thick isotropic plates", Structural Engineering and Mechanics, 69(3), 335-345. DOI: https://doi.org/10.12989/sem.2019.69.3.335.

[8] Fan, H., Chen, Z., Wang, Z., \& Liu, P. (2019), “Buckling of simply supported thin plate with variable thickness under bi-axial compression using perturbation technique", Structural Engineering and Mechanics, 70(5), 525-534. DOI: https:// doi.org/10.12989/sem.2019.70.5.525.

[9] Remil, A., Benrahou, K. H., Draiche, K., Bousahla, A. A., \& Tounsi, A. (2019), "A simple HSDT for bending, buckling and dynamic behavior of laminated composite plates", Structural Engineering and Mechanics, 70(3), 325-337. DOI: https:// doi.org/10.12989/sem.2019.70.3.325.

[10] Kandasamy, R., Dimitri, R., \& Tornabene, F. (2016). Numerical study on the free vibration and thermal buckling behavior of moderately thick functionally graded structures in thermal environments. Composite Structures, 157, 207-221.

[11] Nejati, M., Dimitri, R., Tornabene, F., \& Hossein Yas, M. (2017). Thermal buckling of nanocomposite stiffened cylindrical shells reinforced by functionally graded wavy carbon nanotubes with temperature-dependent properties. Applied Sciences, 7(12), 1223.

[12] Chhorn, B., \& Jung, W. (2020). Evaluation of Buckling Resistance of Basalt Fiber Reinforced Polymer Plate. Iranian Journal of Science and Technology, Transactions of Civil Engineering, 1-12. https://doi.org/10.1007/s40996-019-00344-1.

[13] Chhorn B., \& Jung, W (2019) Parametric study on buckling resistance ofthe thin BFRP (Basalt Fiber Reinforced Polymer) plate subjected to combined loading. J Korean Soc Adv Compos Struct 
10(1):1-9. https://doi.org/10.11004/kosacs.2019.10.1.001.

[14] Carrera, E., \& Valvano, S. (2019). A variable ESL/LW kinematic plate formulation for free-vibration thermoelastic analysis of laminated structures. Journal of Thermal Stresses, 42(4), 452474. http://dx.doi.org/10.1080/01495739.2018.1474513.

[15] Carrera, E., \& Valvano, S. (2017). A variable kinematic shell formulation applied to thermal stress of laminated structures. Journal of Thermal Stresses, 40(7), 803-827. http://dx.doi.org/10.1080/ 01495739.2016 .1253439 .

[16] Topal, U., \& Uzman, Ü. (2008), “Maximization of buckling load of laminated composite plates with central circular holes using MFD method", Structural and Multidisciplinary Optimization., 35(2), 131-139.

[17] Avci A, Kaya S, Daghan, B. Thermal buckling of rectangular laminated plates with a hole. Journal of reinforced plastics and composites 2005; 24(3): 259-272.

[18] Avci, A., Sahin, Ö. S., \& Uyaner, M. (2005), "Thermal buckling of hybrid laminated composite plates with a hole", Composite structures., 68(2), 247-254. https://doi.org/10.1016/j.compstruct. 2004.03.017.
[19] Chen W], Lin PD, Chen LW. Thermal buckling behavior of composite laminated plates with a circular hole. Composite structures 1991; 18(4): 379-397.

[20] Shaterzadeh, A. R., Abolghasemi, S., \& Rezaei, R. (2014), “Finite element analysis of thermal buckling of rectangular laminated composite plates with circular cutout", Journal of thermal stresses., 37(5), 604- 623. https://doi.org/10.1080/01495739. 2014.885322.

[21] Kumar, R. Vijaya, and G. Krishnamohana Rao. (2018), “Thermal Buckling Analysis of Laminated Composite Plate with Square/Rectangular, Elliptical/Circular Cutout", Materials Today: Proceedings., 5(2), 5354-5363. https://doi.org/10.1016/j. matpr.2017.12.121.

[22] Ouinas D, Achour B. Buckling analysis of laminated composite plates $[(\theta /-\theta)]$ containing an elliptical notch. Composites Part B: Engineering 2013; 55: 575-579.

[23] Ounis H, Belarbi MO. On the thermal buckling behavior of laminated composite plates with cutouts. Journal of Applied Engineering Science \& Technology 2017, 3(2): 63-69. 